\title{
Dermatite multifatorial em um canino
}

\author{
[Multifactorial dermatitis in a dog] \\ C.B. Matos ${ }^{1}$, I.M. Madrid ${ }^{1}$, R. Santin ${ }^{2}$, R.H. Azambuja ${ }^{3}$, I. Schuch ${ }^{4}$, \\ M.C.A. Meireles ${ }^{1}$, M.B. Cleff ${ }^{1}$ \\ ${ }^{1}$ Faculdade de Veterinária - Universidade Federal de Pelotas - Pelotas, RS \\ ${ }^{2}$ Universidade Federal do Rio Grande do Sul - Porto Alegre, RS \\ ${ }^{3}$ Técnica em Laboratório - Universidade Federal de Pelotas - Pelotas, RS \\ ${ }^{4}$ Residente - Universidade Federal de Pelotas - Pelotas, RS
}

\begin{abstract}
RESUMO
Relatou-se um caso clínico de dermatite multifatorial em cão, envolvendo Demodex canis, Sporothrix schenckii e bactérias dos gêneros Staphylococcus e Streptococcus. O animal, macho, da raça Pit Bull, com um ano e três meses de idade, apresentou lesões úmidas, hiperêmicas, descamativas e ulcerativas nas regiões do pescoço e do tórax. Exames laboratoriais confirmaram o diagnóstico de infecção concomitante por fungo, bactéria e parasito. A terapia antimicrobiana com moxidectina, itraconazol e amoxicilina foi efetiva, com remissão dos sinais clínicos após 30 dias de tratamento. Este relato salienta a importância do diagnóstico de certeza, que foi determinante para estabelecimento da terapêutica adequada e recuperação do animal.
\end{abstract}

Palavras-chave: cão, demodicose, esporotricose, piodermite

\begin{abstract}
A clinical case of dermatitis multifactorial in a dog was reported, involving Demodex canis, Sporothrix schenckii, and bacteria of the genera Staphylococcus and Streptococcus. The animal, male, Pit Bull, with a year and three months of age had soaked lesions, was hyperemic, scaly and had an ulcer in the neck and chest. Laboratory tests confirmed the diagnosis of concomitant infection by fungi, bacteria and parasites. Antimicrobial therapy with moxidectin, itraconazol and amoxicillin was effective, with remission of clinical signs after 30 days of treatment. This report emphasizes the importance of an accurate diagnosis, which was crucial to establish the correct treatment and recovery of the animal.
\end{abstract}

Keywords: dog, demodicosis, sporotrichosis, pyoderma

\section{INTRODUÇÃO}

As afecções do sistema tegumentar possuem grande importância na clínica de pequenos animais, representando cerca de 30 a $40 \%$ dos casos presenciados na clínica médica (Willense, 2000). Segundo Meneses et al. (2000), as principais dermatopatias de cães e gatos, em ordem decrescente de ocorrência, de acordo com a etiologia, são bacterianas, parasitárias e fúngicas. Entre os principais agentes etiológicos estão bactérias dos gêneros Staphylococcus e Streptococcus, destacando-se Staphylococcus pseudointermedius na maioria dos casos de piodermite canina, e ectoparasitas, como Demodex canis e Sarcoptes scabiei var. canis (Barbosa et al., 2011). Os diagnósticos micológicos na clínica de pequenos animais são crescentes, especialmente naqueles animais que apresentam fatores predisponentes e/ou infecções associadas, favorecendo, assim, a instalação fúngica. Entre as diferentes espécies fúngicas de importância clínica, destacam-se Malassezia pachydermatis, Sporothrix schenckii e os dermatófitos (Muller e Kirk, 2003; Machado et al., 2004; Whittemore e Webb, 2007; Madrid et al., 2010).

Recebido em 6 de setembro de 2011

Aceito em 20 de julho de 2012

E-mail: bohnencarol@gmail.com 
Inúmeros agentes podem estar envolvidos nas dermatopatias, levando a diferentes quadros clínicos, tanto localizados quanto disseminados. Os casos em que há associação de microrganismos requerem uma atenção redobrada, para que se possa instituir terapêutica adequada (Pereira et al., 2005). Assim, o objetivo deste trabalho foi relatar um caso de dermatite multifatorial em um cão da raça Pit Bull, envolvendo ectoparasita, bactérias e fungo.

\section{RELATO DO CASO}

Um cão, macho, da raça Pit Bull, com um ano e três meses de idade, foi encaminhado para atendimento clínico em Ambulatório do Hospital Veterinário Escola, apresentando lesões úmidas, hiperêmicas, descamativas e ulcerativas nas regiões do pescoço e do tórax há aproximadamente 45 dias. $\mathrm{O}$ proprietário relatou que, inicialmente, as lesões eram pequenas e localizadas, e com a progressão da enfermidade houve disseminação e agravamento das lesões. No exame clínico geral, foram avaliados frequência cardiorrespiratória, tempo de preenchimento capilar e temperatura, os quais encontravam-se dentro dos valores fisiológicos para a espécie.

Para o diagnóstico definitivo, foram colhidas amostras de suabes das secreções de pele e raspado cutâneo com coleta de pelos e crostas. As amostras foram acondicionadas e encaminhadas ao laboratório para realização de exame direto da amostra clínica e cultivo microbiológico.

Para a pesquisa de ácaros, foi realizado um raspado cutâneo profundo com lâmina de bisturi até produção de sangramento para a visualização, em microscópio óptico, de ácaros adultos ou formas imaturas. O exame parasitológico revelou a presença do ácaro Demodex canis, sendo instituída terapia com moxidectina (Cydectin $\left.{ }^{\circledR}\right)$, na dose de $0,5 \mathrm{mg} / \mathrm{kg}$, por via oral, em quatro aplicações, com intervalos semanais.

Para isolamento fúngico, as amostras foram cultivadas em ágar Sabouraud dextrose acrescido de cloranfenicol e cicloheximida, e incubadas a $32^{\circ} \mathrm{C}$ por um período de até três semanas com observação diária. Após o crescimento fúngico, foram avaliadas as características macro e micromorfológicas das colônias. A $32^{\circ} \mathrm{C}$ as colônias apresentavam coloração cremeacastanhada e microscopicamente filamentos finos hialinos septados com conídios piriformes dispostos simpodialmente no ápice do conidióforo, compatível com Sporothrix schenckii. A confirmação do agente etiológico foi obtida com a conversão da fase filamentosa a leveduriforme em ágar Sabouraud dextrose acrescido de extrato de levedura, em temperatura de $37^{\circ} \mathrm{C}$. A terapia antifúngica no cão foi realizada com itraconazol, na dose de $10 \mathrm{mg} / \mathrm{kg}$, por via oral, uma vez ao dia por um período de 60 dias.

Para identificação bacteriana, foram realizados provas e testes bioquímicos que resultaram na identificação de Staphylococcus spp. e Streptococcus spp., diferenciados pela prova bioquímica de catalase. No tratamento inicial, foi utilizado sulfametoxazol associado a trimetropina, por via oral, durante uma semana, 20mg/kg, duas vezes ao dia; nas três semanas seguintes à antibioticoterapia, usou-se amoxicilina com clavulanato, $20 \mathrm{mg} / \mathrm{kg}$, três vezes ao dia. Os resultados obtidos pelos tratamentos foram satisfatórios, com visível melhora dos sinais clínicos.

\section{DISCUSSÃO}

Dentre as dermatopatias de maior ocorrência em cães, destacam-se as piodermites bacterianas, sendo que bactérias Gram-positivas predominam nos isolamentos (Barbosa et al., 2011). Isolados de Staphylococcus spp. e Streptococcus spp. são bactérias comumente descritas como agentes causadores de piodermites secundárias (Conte, 2008). A infecção bacteriana é frequente em doenças dermatológicas, sendo secundária a um problema subjacente que altera a resistência da pele (Pena, 2007). A associação de bactérias do gênero Staphylococcus com o Demodex canis tem sido descrita em quadros de dermatites (Guimarães et al., 2001). Santarem (2007) afirmou que em $90 \%$ dos casos de demodicose há o envolvimento de bactérias Gram-positivas, responsáveis por causar piodermites.

Casos de infecções fúngica e parasitária concomitantes são raramente diagnosticados na clínica de pequenos animais e pouco descritos na literatura. Nobre et al. (1998) obtiveram 22,2\% de associação de malasseziose e demodicose em cães com dermatites recidivantes, enquanto 
Machado et al. (2004) observaram que somente $12,2 \%$ dos cães apresentavam associação da malasseziose e demodicose.

Casos de infecção mista de S. schenckii com agentes parasitários ou fúngicos são raros, havendo somente um caso de esporotricose e criptococose associadas em um cão (Shany, 2000). Nesse sentido, o presente relato foi o primeiro encontrado na literatura consultada, pois descreve um caso de infecção mista de esporotricose e demodicose em um cão. Este relato é semelhante ao descrito por Pereira et al. (2005) em gato com demodicose, esporotricose e pediculose coinfectado pelo vírus da imunodeficiência felina (FIV) e pelo vírus da leucemia felina (FeLV).

A esporotricose, micose causada pelo fungo dimórfico $S$. schenckii, é uma doença considerada rara em cães (Londero et al., 1964; Schubach e Schubach, 2000; Madrid et al., 2007). Entretanto, casos esporádicos têm sido descritos nessa espécie em diferentes estados do Brasil (Larsson et al., 1993; Souza et al., 2009), assim como, recentemente, foi relatado um grande número de casos em cães nos estados do Rio de Janeiro e Rio Grande do Sul (Schubach et al., 2006; Madrid et al., 2007). As alterações cutâneas observadas no presente relato não apresentavam padrão específico, assemelhandose a uma infecção parasitária e/ou bacteriana. Entretanto, a presença de áreas ulceradas pode ser sugestiva de esporotricose, uma vez que as lesões desta micose caracterizam-se por nódulos firmes que evoluem a áreas alopécicas e/ou ulceradas (Schubach e Schubach, 2000; Madrid et al., 2007; Souza et al., 2009). Muitos sinais clínicos, como alopecia, eritema, descamação, pápulas, liquenificação, hiperpigmentação, pústulas, erosões, crostas e/ou úlceras decorrentes de piodermatite secundária superficial ou profunda (Paradis, 1999; Mueller, 2004), são observados em casos de demodicose.

A demodicose é uma doença parasitária causada pelo ácaro Demodex canis, com frequência muito variável na clínica de pequenos animais. Bellato et al. (2003), em Santa Catarina, detectaram que $52,8 \%$ dos cães atendidos nas clínicas eram acometidos por ectoparasitas. Outros relatos brasileiros descreveram $D$. canis como o agente causal de $40 \%$ a $48,2 \%$ dos casos de sarna canina (Delayte et al., 2006; Santarém, 2007). Na Índia e no Canadá, observou-se baixa prevalência de demodicose em cerca de $3 \%$ e $2,3 \%$ dos cães, respectivamente (Scott e Paradis, 1990; Nayak et al., 1997). Essa variação está relacionada, possivelmente, às dificuldades em confirmar o $D$. canis nos raspados cutâneos (Muller e Kirk, 2003). Esse ectoparasita é considerado residente normal da pele de cães, sendo que estados de imunodeficiência favorecem sua multiplicação, tornando-o patogênico. Vários autores citaram o aparecimento da demodicose quando ocorrem estados de imunodeficiência geral do animal (Muller e Kirk, 2003), como no caso relatado, em que o animal possuía vários agentes responsáveis pela dermatopatia.

Para o sucesso do tratamento das piodermites caninas, deve-se ter como princípios básicos a escolha adequada do antibiótico, a dose efetiva e a manutenção da terapia por tempo adequado para a erradicação do agente, assim como a eliminação dos fatores predisponentes ou perpetuantes (Barbosa et al., 2011). Neste caso, para a infecção bacteriana, foi prescrito sulfametoxazol associado ao trimetoprim; como a resposta inicial não foi efetiva, optou-se pela substituição do antibiótico por amoxicilina com clavulanato, o que levou a uma melhora significativa do quadro clínico. A resistência bacteriana tem sido relatada, e trata-se de um problema emergente; entretanto, segundo Barbosa et al. (2011), cerca de 90\% dos Staphylococcus pseudointermedius isolados de cães com piodermites são sensíveis à amoxicilina com clavulanato.

Os protocolos terapêuticos instituídos para esporotricose e demodicose apresentaram resultados satisfatórios, semelhantes aos descritos por Schubach e Schubach (2000). O itraconazol apresenta amplo espectro de ação tanto nas micoses superficiais como nas sistêmicas, sendo considerado o antifúngico de eleição para o tratamento da esporotricose em humanos e animais (Schubach e Schubach, 2000; Schubach et al., 2006; Madrid et al., 2010). A moxidectina utilizada no presente relato é descrita como eficaz na maioria dos tratamentos de demodicose em cães (Paradis, 1999).

O quadro clínico apresentado pelo animal do presente relato provavelmente está relacionado a um desequilíbrio do sistema imune, uma vez que se tratava de um animal jovem. Entretanto, um 
estudo mais detalhado objetivando identificar as causas que propiciaram o desenvolvimento deste quadro clínico não foi realizado, principalmente porque o animal pertencia a uma família de baixa renda. Em razão da grande importância das dermatopatias na clínica veterinária e da possibilidade de envolvimento de inúmeros agentes etiológicos, a realização de exames complementares é uma medida imprescindível para o estabelecimento do diagnóstico de certeza e, consequentemente, para uma adequada terapia antimicrobiana, a fim de se obter a cura clínica.

\section{AGRADECIMENTOS}

Os autores agradecem ao Conselho Nacional de Desenvolvimento Tecnológico (CNPq), à Coordenação de Aperfeiçoamento de Pessoal de Nível Superior (CAPES) e à Fundação de Amparo à Pesquisa do Estado do Rio Grande do Sul (FAPERGS), pelo suporte financeiro.

\section{REFERÊNCIAS}

BARBOSA, D.C.; SANTOS, L.L.; WARTH, J.F. et al. Dermatopatias piogênicas em cães de abrigo e padrões de sensibilidade aos antimicrobianos in vitro de cepas de Staphylococcus pseudintermedius. Clin. Vet., n.93, p.72-78, 2011.

BELLATO, V.; SARTOR A.A.; SOUZA A.P. et al. Ectoparasitoses em caninos no município de Lages, Santa Catarina, Brasil. Rev. Bras. Parasitol. Vet., v.12, p.95-98, 2003

CONTE, A.P. Demodicose canina generalizada: relato de caso. 2008. 12f. Monografia (Curso de Especialização Latu Sensu em Clínica Médica e Cirúrgica de Pequenos Animais) Curitiba.

DELAYTE, E.H.; OTSUKA, M.; LARSSON, C.E. et al. Eficácia das lactonasmacrocíclicas sistêmicas (ivermectina e moxidectina) na terapia da demodicidose canina generalizada. Arq. Bras. Med. Vet. Zootec., v.58, p.31-38, 2006.

GUIMARÃES, J.H.; TUCCI, E.C.; BARROSBATTESTI, D.M. Ectoparasitos de importância Veterinária. São Paulo: Plêiade, 2001. 218p.

LARSSON, C.E.; DAGLI, M.L.Z.; PAULA, C.R.; MICHALANY, N.S. Esporotricose canina - relato de caso insólito. In: CONGRESSO BRASILEIRO DE CLÍNICOS VETERINÁRIOS DE PEQUENOS ANIMAIS, 15., 1993, Rio de Janeiro. Anais... Rio de Janeiro: Anclivepa, 1993, p.9.

LONDERO, A.T.; CASTRO, R.M.; FISCHMAN, O. Two cases of sporotrichosis in dogs in Brazil. Sabouraudia, v.18, p.273-274, 1964.
MACHADO, M.L.S.; APPELT, C.E.; FERREIRO, L. Dermatófitos e leveduras isolados da pele de cães com dermatopatias diversas. Acta Sci. Vet., v.32, p.225232,2004

MADRID, I.M; MATTEI, A.S; MARTINS, A.A. et al. Feline sporotrichosis in the southern region of Rio Grande do Sul, Brazil: clinical, zoonotic and therapeutic aspects. Zoon. Pub. Health, v.57, p.151154, 2010.

MADRID, I.M.; SANTOS JR, R.; SAMPAIO JR, D.P. et al. Esporotricose canina: relato de três casos. Acta Sci. Vet., v.35, p.105-108, 2007.

MENESES, A.M.C.; CARDOSO, M.J.L.; FRANCO, S.R.V.S. et al. Ocorrência das dermatopatias em cães e gatos. Rev. Bras. Cienc. Vet., v.2, p.20, 2000.

MUELLER, R.S. Treatment protocols for demodicosis: an evidence-based review. Vet. Dermatol., v.15, p.75-89, 2004.

MULLER, G.H.; KIRK, R.W. Dermatologia de pequenos animais. Rio de Janeiro: Interlivros, 2003. p.88-103.

NAYAK, D.C.; TRIPATY, S.B.; DEY, P.C. et al. Prevalence of canine demodicosis in Orissa (Índia). Vet. Parasitol., v.73, p.347-352, 1997.

NOBRE, M.; MEIRELES, M.; GASPAR, L.F. et al. Malassezia pachydermatis e outros agentes infecciosos nas otites externas e dermatites em cães. Cienc. Rural, v.28, p.447-452, 1998.

PARADIS, M. New approaches to the treatment of canine demodicosis. Vet. Clin. North Am. Small Anim. Pract., v.29, p.1425-1436, 1999.

PENA, S.B. Frequência de dermatopatias infecciosas, parasitárias e neoplásicas em cães na região de Graça, São Paulo - Brasil, 2009. 12f. Dissertação (Mestrado em Medicina Veterinária) - Faculdade de Medicina Veterinária e Zootecnia da UNESP, São Paulo.

PEREIRA, S.A.; SCHUBACH, T.M.P.; FIGUEIREDO, F.B. et al. Demodicose associada à esporotricose e pediculose em gato co-infectado por FIV/FeLV. Acta Sci. Vet, v.33, p.75-78, 2005.

SANTAREM, V. Demodicose canina: revisão. Clin. Vet., v.69, p.86-98, 2007.

SCHUBACH, T.M.P.; SCHUBACH, A.O. Esporotricose em gatos e cães: revisão. Clin. Vet., n.29, p.21-24, 2000.

SCHUBACH, T.M.P.; SCHUBACH, A.; OKAMOTO, T. et al. Canine sporotrichosis in Rio de Janeiro, Brazil: clinical presentation, laboratory diagnosis and therapeutic response in 44 cases (19982003). Med. Mycol., v.44, p.87-92, 2006. 
SCOTT, D.W.; PARADIS, M. A survey of canine and feline skin disorders seen in a university practice: small animal clinic, University of Montreal, Sainthyacinthe, Quebec (1987-1988). Can. Vet. J., v.31, p.830-834, 1990

SHANY, M.A mixed fungal infection in a dog: sporotrichosis and cryptococcosis. Can. Vet. J., v.41, p.799-800, 2000.
SOUZA, N.T.; NASCIMENTO, A.C.B.M.; SOUZA,

J.O.T. et al. Esporotricose canina: relato de caso. Arq. Bras. Med. Vet. Zootec., v.61, p.572-576, 2009.

WILLENSE, T. Dermatologia clínica de cães e gatos. São Paulo: Manole, p.117, 2000

WHITTEMORE, J.C.; WEBB, C.B. Successful treatment of nasal sporotrichosis in a dog. Can. Vet. J., v.48, p.411-414, 2007. 